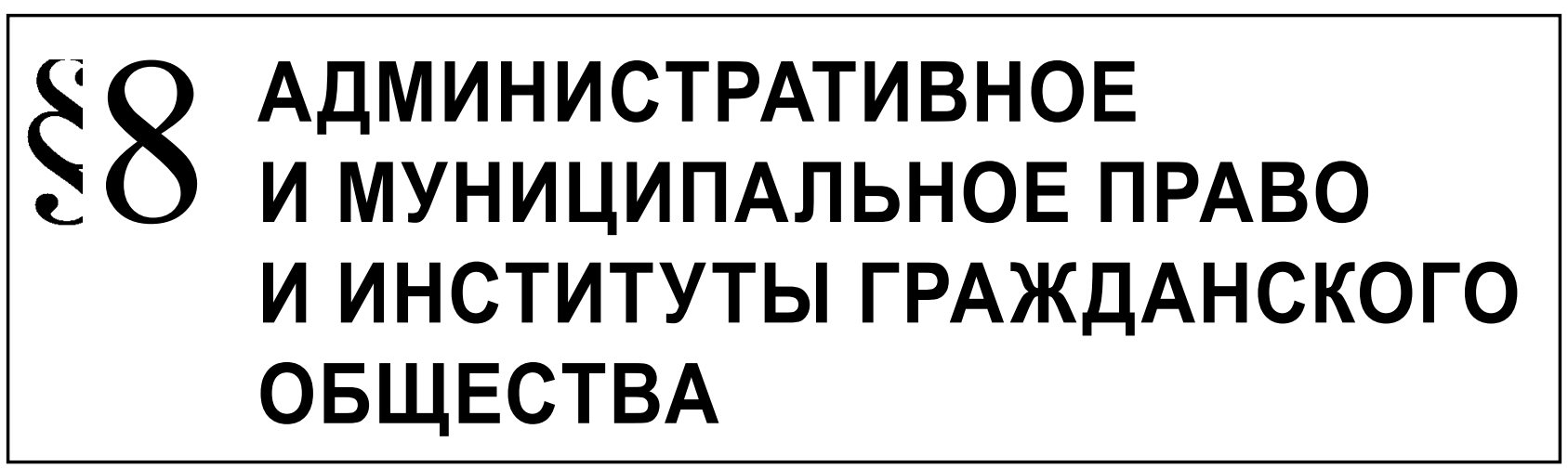

Грудцына Л.Ю.

\title{
ФИЛОСОФСКО-ПРАВОВАЯ КОНЦЕПЦИЯ ГРАЖДАНСКОГО ОБЩЕСТВА КАК САМООРГАНИЗУЮЩЕЙСЯ СОЦИАЛЬНОЙ СИСТЕМЫ: ОТ ГЕГЕЛЯ ДО НАШИХ ДНЕЙ
}

Аннотация: Предметом исследования является природа и сущность гражданского общества как самоорганизующейся сложной социальной системы, развитие и качественное преобразование элементов (институтов) которой приводит к новому качеству самой системы согласно законам синергетики. Если предположить (согласно гегелевской трактовке), что общество представляет собой институты гражданского общества плюс государство (в широком смысле этого понятия), то все что не относится к государству (его органам, структурам, обеспечивающим функционирование государственного механизма принуждения и т.д.), это гражданское общество. И наоборот. Все, что не относится к гражданскому обществу, это государство. Но на деле (сейчас в России) это не так. По нашему мнению, появилась третья часть, которую Гегель почему-то (слишком обобщив конструкцию) не включил в свою формулу. Это все, что не относится ни к государству, ни к гражданскому обществу, это пассивная масса. Назовем ее "предуровень развития гражданского общества", который, по большому счету, и является объектом манипуляции государства, и основной пассивно-безразличной силой, при молчаливом согласии которой государство правит. В статье автор делает попытку, с привлечением научных методов, применяемых в синергетике, предложить альтернативную гегелевской формулу разграничения гражданского общества и государства не как разновеликих и противоборствующих друг с другом систем, а как необходимых друг другу сложносоставных элементов единой социальной системы, представляя эту научную идею в виде арифметической прогрессии, в которой предуровень гражданского общества - «масса», следующий уровень - само гражданское общество, осознавшее себя, развивающееся и усложняющееся, следующий уровень - правовое государство (идеал, к которому нужно стремиться). В данном случае государство станет не слагаемым, а результатом в формуле. Если выдвинуть антитезу формуле Гегеля (у которого принято противопоставление государства и гражданского общества как двух уравновешивающих друг друга полюсов, и поиск таким образом гармонии между ними), а именно: если государство рассматривать не как слагаемое в формуле, а как результат, итог, следующая ступень развития самоорганизующегося гражданского общества как динамической системы. Иными словами, предуровень гражданского общества - "пассивная масса», следующий уровень - само гражданское общество, осознавшее себя, развивающееся и усложняющееся, следующий уровень - правовое государство (идеал, к которому нужно стремиться). В данном случае государство станет не слагаемым, а результатом в формуле. Но подобная формула должна быть не просто суммой слагаемых, а чем-то типа арифметической прогрессии.

Ключевые слова: правовое государство, гражданское общество, социальная система, государственная власть, управление, конституция, закон, демократия, свобода, политика 
$\Pi$ равовое государство может существовать только там и тогда, где и когда существует гражданское общество. Иное дело, что именно представляет собой гражданское общество. Ведь это отнюдь не то, что формально выходит за пределы государственных структур. Если наблюдается «огосударствление» общественных институтов, то граница, разделяющая общество и государство, становится аморфной и в той или иной мере смещается в сферу государственной власти (по Гегелю: власти как «неизбежной необходимости» существования гражданского общества ${ }^{1}$ ), формируя в ней псевдообщественные институты.

Объективно складывающееся положение дел тщательно камуфлируется властью, которая инициирует и создает типовые структуры конституционной модели гражданского общества «сверху», а не «снизу», как это можно видеть в классических образцах, сформулированных в научных трудах и реализованных на практике в развитых европейских странах. Но с учетом того, что в силу могущества нынешней властной вертикали и слабости этого формируемого искусственно гражданского общества его объективный потенциал в значительной мере перемещается в сферу государства и жестко контролируемых им областей государственного управления. Как раз в силу этого искусственно создаваемые государством конституционные институты гражданского общества оказываются изначально обескровленными и весьма пассивными, что можно наблюдать в низкой политической активности и политической самодеятельности подавляющей части населения страны. То, что слишком активно власть или подавляет или эффективно регулирует, а то, что пассивно, она поддерживает, возмещая необходимую для демократической страны инициативу граждан инициативами самой власти, в пользу ее основной партии и вырастающих вокруг нее формально неформальных структур и движений, которые повсеместно именуют прокремлевскими.

Если исходить из определения гражданского общества, данного А.В. Лагуткиным, ${ }^{2}$ то институты гражданского общества существуют в государстве, не подменяя и не заменяя его. Возможно ли и необходимо ли их разграничение с институтами госу-

\footnotetext{
1 См.: Гегель Г.В.Ф. Философия права. М., 1990. С. 225.

2 Гражданское общество - это сообщество независимых субъектов (граждан) внутри государства, вырабатывающих моральные и материальные ценности в интересах самого сообщества и государства (Лагуткин А.В. Россия на распутье: куда пойдем? - М.: Юркомпани, 2013. - С. 3).
}

дарства? Являются ли они антагонистами и, вместе с тем, образуют ли единую сложносоставную и самоорганизующуюся социальную систему?

Как известно, идею разграничения гражданского общества и государства предложил Г.В.Ф. Гегель. Общество представляет собой, согласно Гегелю, сложную динамичную систему, в которой взаимодействуют государство и институты гражданского общества. Иными словами, гражданское общество - это не государственная часть общества, которая основана на автономии индивидов. Государство и гражданское общество относительно самостоятельны. Причем, они - не некая застывшая конструкция, а характеристика реального развития, происходящих в обществе процессов.

Если предположить (согласно гегелевской трактовке), что общество представляет собой институты гражданского общества плюс государство (в широком смысле этого понятия), то все что не относится к государству (его органам, структурам, обеспечивающим функционирование государственного механизма принуждения и т.д.), это гражданское общество. И наоборот. Все, что не относится к гражданскому обществу, это государство. Но на деле (сейчас в России) это не так. По нашему мнению, появилась третья часть, которую Гегель почемуто (слишком обобщив конструкцию) не включил в свою формулу. Это все, что не относится ни к государству, ни к гражданскому обществу, это пассивная масса. Назовем ее «предуровень развития гражданского общества», который, по большому счету, и является объектом манипуляции государства, и основной пассивно-безразличной силой, при молчаливом согласии которой государство правит. ${ }^{3}$

Если выдвинуть антитезу формуле Гегеля (у которого принято противопоставление государства и гражданского общества как двух уравновешивающих друг друга полюсов, и поиск таким образом гармонии между ними), а именно: если государство рассматривать не как слагаемое в формуле, а как результат, итог, следующая ступень развития самоорганизующегося гражданского общества как динамической системы. ${ }^{4}$ Иными

\footnotetext{
Грудцына Л.Ю. Гражданское общество и частное право // Новый юридический журнал. 2013. № 2.

4 Динамическая система представляет собой математическую модель некоторого объекта, процесса или явления. Динамическая система также может быть представлена как система, обладающая состоянием. При таком подходе, динамическая система описывает (в целом) динамику некоторого процесса, а именно: процесс перехода системы из одного состояния в другое (см.: Википедия, http://ru.wikipedia.org).
} 
словами, предуровень гражданского общества «пассивная масса», следующий уровень - само гражданское общество, осознавшее себя, развивающееся и усложняющееся, следующий уровень правовое государство (идеал, к которому нужно стремиться).

В данном случае государство станет не слагаемым, а результатом в формуле. Но подобная формула должна быть не просто суммой слагаемых, а чем-то типа арифметической прогрессии.... Представляется, об этом еще предстоит подумать ученым.

Возникновение гражданского общества связано с развитием частной собственности, которая стала стимулом для творческой активности человека, его заинтересованности в развитии производства, основой возникновения среднего класса. ${ }^{5}$ Отсюда в идеале гражданское общество - это свободное, плюралистическое рыночное общество, где нет места режиму личной власти, тоталитаризму, насилию над людьми, где уважают закон и мораль, принципы гуманизма и справедливости, где центральное место занимает человек, гражданин, личность.

Скорее следует согласиться (но не во всем) с К. Марксом, нежели с идеализмом Гегеля, выдвинувшим как константу и непреложную истину «действительную идею». ${ }^{6}$ Рассуждения К. Маркса менее абстрактны, а потому более объяснимы, в том числе - с позиций исторического развития.

Фактом является то, что государство возникает из множества самых разных индивидов, существующего в виде членов семей и членов гражданского общества. Но возникнув и укрепившись исторически, государства в мире становятся сильными субъектами, управляющими проживающим на территории государства населением, регулирующими множество общественных, социально-экономических процессов, происходящих в государстве.

Теперь можно признать следующее: государство является необходимым фактором создания и самого факта существования гражданского общества. Если не будет силы и государственной воли (принуждения) в определенных вопросах общественной жизни - все скатится к беспорядкам и хаосу. Не в последнюю очередь это касается гражданского общества, саморегулируемой системы, нуждающейся в постоянном контроле со стороны государства.

\footnotetext{
5 Подробнее см.: Грудцына Л.Ю. Частная собственность и гражданское общество в России // Адвокат. 2009. № 8.

6 См.: Гегель Г.В.Ф. Философия права. М., 1990. С. 225.
}

Все это лишь демонстрирует всю ту же объективную взаимосвязь государства и гражданского общества (в котором государство, безусловно, доминирует) применительно к особым примерам. Воистину гражданское общество и государство представляют собой единство и борьбу противоположностей. «В гражданском обществе каждый для себя - цель, - отмечал Георг Вильгельм Фридрих Гегель, - все остальное для него ничто». ${ }^{7}$ Или: «Гражданское общество является ареной борьбы частных индивидуальных интересов, войны всех против всех». ${ }^{8}$ И как раз эта-то война, которая сама является следствием социального единства и вытекающих из него ограничений, рождает необходимость мощного интегрирующего начала, коим и является государство.

Позже эти идеи развил Карл Маркс: «Там, где политическое государство достигло своей действительно развитой формы, человек не только в мыслях, в сознании, но и в действительности, в жизни, ведет двойную жизнь: жизнь в политической общности, в которой он признает себя общественным существом, и жизнь в гражданском обществе, в котором он действует как частное лицо, рассматривает других людей как средство, низводит себя самого до роли средства и становится игрушкой чуждых сил». ${ }^{9}$

При всем желании ни один политический строй или режим не в состоянии свести на нет частную жизнь граждан, которая в своих разнообразных проявлениях и составляет то, что мы называем гражданским обществом. Иными словами, нельзя устранить гражданское общество, не устраняя одновременно самого государства. Государство зиждется на интересах, дающих ему связь с объективным миром через потребности людей. Если чисто теоретически эту связь разорвать, государство потеряет свою материальную плоть и поневоле исчезнет. Даже псевдогражданское общество, сформированное в рамках государства им самим, каким бы масштабным оно не было, не способно перечеркнуть тот факт, что состоит оно из вполне материальных людей, все потребности и интересы которых объять невозможно. Государство по природе

\footnotetext{
См.: Гегель Г.В.Ф. Философия права. М., 1990. С. 228. Об этом также писал Платон.

8 См.: Там же. С. 330. Гегель здесь использует известную характеристику Томасом Гоббсом естественного состояния, которое, по его определению, есть «война всех против всех».

9 См.: Маркс К. К еврейскому вопросу // Маркс К., Энгельс Ф. Соч. Т. 1. С. $390-391$.
} 
своей стремится и может контролировать лишь всеобщее, но всеобщее к единичному несводимо и из него невыводимо. Аристотелевский парадокс целостности или, говоря языком теории систем эмерджентность, справедлив для любого целого, в том числе, и социального.

Гражданское общество нельзя трактовать как антитезу государства, ибо гражданское общество и государство - это теснейшим образом объективно взаимосвязанные и взаимозависимые социальные и политико-правовые явления, своего рода тандем, где ведущая роль в идеале должна принадлежать гражданскому обществу, на стороне которого формирование материального субстрата государства - общезначимого интереса. При слабо развитых институтах демократии или в тоталитарных государствах эта картина оказывается сильно закамуфлированной: государство как субъект государственного управления оказывает воздействие на гражданское общество (и достаточно активное) как его объект.

Устранение интегрирующего государственного начала, противостоящего индивидуализму субъектов гражданского общества, превращает гражданское общество в ничем не связанную совокупность индивидов, что способно привести к воцарению анархии. ${ }^{10}$ Здесь не будет ни государства, ни гражданского общества. История дает множество примеров, когда из-за ослабления или гибели государства общество погружалось в анархию и смуту со всеми сопутствующими им бедствиями и кровопролитиями. Достаточно вспомнить Россию конца XVI - начала XVII века. Самая яркая иллюстрация из новейшей отечественной истории перестройка и реформы, которые привели к крушению Советского Союза.

Кстати говоря, современное российское государство вряд ли можно назвать сильным. Его социалистический предшественник был не в пример мощнее. Слабости нового российского государства сопутствует аморфность гражданского общества и процесса его формирования. Само же гражданское общество в существенной мере замещается его политическим суррогатом, формирующимся новой номенклатурой в форме создаваемых ею политических псевдообщественных организациях.

Можно говорить также об «активном» или «пассивном» гражданском обществе. Поскольку

10 См.: Поздняков Э.А. Российское гражданское общество. Иллюзии и реальность // Политический класс. 2006. № 22. C. 6-7. гражданское общество есть сфера действия эгоистических интересов индивидов, более того, «войны всех против всех», то применение по отношению к нему слова «активное» следовало бы по логике вещей понимать в смысле особо активного ведения этой самой «войны». Если же речь идет о состоянии гражданского общества, то о нем больше может сказать степень его диссоциации. Гражданское общество как сфера господства частного, эгоистического интереса, будучи неподконтрольным государству и полностью предоставленным самому себе, движется в направлении анархии.

Основным компонентом любой социальной системы всегда выступает человек как социальное существо. Как верно писал В.Г. Афанасьев, человек есть последний, в известном смысле слова элементарный носитель социального системного качества. В то же время, будучи компонентом любой социальной системы, воплощением ее сущности, человек есть лишь часть социальной системы. Только будучи включен в определенную общественную систему, индивид обретает свою социальную сущность. ${ }^{11}$

Действительно, опираясь на эту научную теорию, применительно к рассматриваемой в статье проблеме можно сделать следующий важный вывод: если человек является компонентом (элементом) социальной системы, то его нахождение в ней предполагает выполнение человеком определенных функций в этой системе, которые, во-первых, структурно связывают его с системой, во-вторых, меняют саму систему. Таким образом, и человек в отдельности и сама система в целом развиваются, обретая новые качества.

Все это согласуется с теорией сложных систем (синергетикой), согласно которой структура системы (в нашем случае - системы гражданского общества) определяется не как константа, а как ее состояние (в нашем случае - неустойчивое и меняющееся состояние взаимодействия элементов гражданского общества между собой и с государством), возникающее в результате многовариантного и неоднозначного поведения таких многоэлементных структур или многофакторных сред, которые не деградируют к стандартному для замкнутых систем усреднению термодинамического типа, а развиваются вследствие открытости, притока энергии извне, нелинейности внутренних процессов, появ-

11 См.: Афанасьев В.Г. Общество: системность, познание и управление. - М.: Политиздат, 1981. - С. 23. 
ления особых режимов с обострением и наличия более одного устойчивого состояния.

Чем развитие конкретного человека в его взаимодействии с другими людьми (элементами системы) будет интенсивнее, тем быстрее будет совершенствоваться сама система. Но не следует забывать и о том, что само взаимодействие членов гражданского общества одновременно является и способом развития всей системы (изменением ее состояния в пространстве и во времени), и в силу нестабильности (свойственной любому развитию) - риском для системы в целом, ведущему к ее неустойчивому состоянию и, в некоторых случаях, к разрушению. ${ }^{12}$

Иными словами, на наш взгляд, чем свободнее и интенсивнее будет развиваться человек, индивиды, народ конкретного государства, тем быстрее его развитие будет (по некоторым направлениям) переходить в саморазвитие и формирование институтов гражданского общества. Это в идеале. Однако, согласно теории сложных систем, существует и риск, связанный с нестабильностью и неустойчивым состоянием.

Самоорганизация граждан и наличие неконтролируемых государством сфер так называемой «гражданской активности» (повторим, что в этом случае государство делает определенные волевые усилия по самоограничению собственной власти во имя полноценного развития всей системы) является важным симптомом благополучного развития всей системы, сравнимым с наличием иммунитета в организме. Иными словами, чем больше возможностей предоставляет государство как управляющий субъект, являющийся частью системы (государствообщество), управляемому объекту (гражданскому обществу) в сфере самоидентификации и самоорганизации, тем меньше риск «заболевания» всей системы как единого организма, части которого могут влиять друг на друга. Именно государство в данном случае может являться как рычагом, так и тормозом всего процесса. В современной России это особенно актуально, ведь политическое устройство, как верно отметил Р.Г. Абдулатипов, - это один из элементов отражения социального опыта народов страны и культурного, цивилизованного устройства форм их развития и взаимодействия. ${ }^{13}$

12 Грудцына Л.Ю. Развитие институтов гражданского общества в аспекте частного и публичного права // Образование и право. 2013. № 7(47).

13 См.: Абдулатипов Р.Г. Национальный вопрос и государственное устройство России. - М.: Славянский диалог, 2000. - C. 33 .
На наш взгляд, построение государством «сверху» в условиях его общей неразвитости и наличии массовых стереотипов советского тоталитаризма в общественном сознании гражданского общества имеет ряд плюсов, хотя бы с позиций метода системного анализа.

В-первых, государству (и не только ему) легче управлять обществом как подсистемой, когда основные элементы системы (государство-общество) упорядочены, соотнесены друг с другом, когда понятны их внутренние связи и соподчиненность. Сложнее (и почти невозможно) управлять хаосом, беспорядком, в котором управляемые элементы разрозненны и не имеют четких связей друг с другом.

Во-вторых, в современной России, где проживает более 200 различных народов и этнических групп, различающихся по языку, самобытным особенностям своей материальной и духовной культуры, конфессиональной принадлежности, необходимость «управляемой свободы» очевидна и вполне логична. Государство не просто является регулятором и реформатором данной сферы, но и сам факт государственного вмешательства в процессы формирования институтов гражданского общества - процесс во многом естественный и неизбежный с учетом исторических традиций нашей страны. Россия - это община, как продукт эволюции сообщества народов, это и общность, как совокупность людей, имеющих общую историю, на базе которой формируются общие духовно-нравственные признаки. Взаимовлияние культур и традиций многих народов шло веками вокруг русского этноса. ${ }^{14}$

Тем не менее, нельзя забывать и об ответственности власти, стремящейся создать институты гражданского общества, поскольку этот в общемто позитивный процесс может быть использован в качестве особого инструмента государственного управления, для манипулирования объективными процессами в социуме, где при наличии демократических предпосылок, сколько бы слабыми они не были, гражданское общество неизбежно вырастает и снизу. Поэтому в идеале приоритет в государственном управлении должен быть отдан именно содействию в формировании гражданского общества, а не в административном создании удобных власти его институтов.

14 См.: Абдулатипов Р.Г. Там же. - С. 27. 
Библиография:

1. Абдулатипов Р.Г. Национальный вопрос и государственное устройство России. - М.: Славянский диалог, 2000. - С. 33.

2. Афанасьев В.Г. Общество: системность, познание и управление. - М.: Политиздат, 1981. - С. 23.

3. Гегель Г.В.Ф. Философия права. М., 1990. С. 225.

4. Грудцына Л.Ю. Развитие институтов гражданского общества в аспекте частного и публичного права // Образование и право. 2013. № 7(47).

5. Грудцына Л.Ю. Частная собственность и гражданское общество в России // Адвокат. 2009. № 8.

6. Лагуткин А.В. Россия на распутье: куда пойдем?-М.: Юркомпани, 2013. - С. 3.

7. Грудцына Л.Ю. Гражданское общество и частное право // Новый юридический журнал. 2013. № 2.

8. Маркс К. К еврейскому вопросу // Маркс К., Энгельс Ф. Соч. Т. 1. С. 390-391.

9. Поздняков Э.А. Российское гражданское общество. Иллюзии и реальность // Политический класс. 2006. № 22. - С. 6-7.

10. Щупленков О.В., Щупленков Н.О. Конституционные основы информационной свободы в России // NB: Вопросы права и политики. - 2013. - 10. - C. 35-92. DOI: 10.7256/2305-9699.2013.10.9617. URL: http://www.e-notabene.ru/lr/article_9617.html

11. Лапин А.Е., Петрова Ю.А. К вопросу о реализации полномочий представительных органов местного самоуправления в Российской Федерации // Административное и муниципальное право. - 2011. - 4. - C. 24-33.

12. Грудцына Л.Ю., Петров С.М. Власть и гражданское общество в России: взаимодействие и противостояние // Административное и муниципальное право. - 2012. - 1. - С. 19-29.

13. Бондарчук И.В. Легализация общественных организаций и политических партий в механизме защиты конституционного строя Украины // NB: Вопросы права и политики. - 2013. - 6. - C. 135-151. DOI: 10.7256/2305-9699.2013.6.6292. URL: http://www.e-notabene.ru/lr/article_6292.html

14. И. Д. Короева Философия взаимодействия власти и народа // Политика и Общество. - 2012. - 4. - С. $18-24$.

15. Трофимов В.В. Участие структур гражданского общества в правообразующих правоотношениях как форма выражения народовластия // NB: Вопросы права и политики. - 2012. - 5. - C. 147-170. URL: http://www.e-notabene.ru/lr/article_364.html

\section{References:}

1. Abdulatipov R.G. Natsional'nyi vopros i gosudarstvennoe ustroistvo Rossii. — M.: Slavyanskii dialog, 2000. — S. 33.

2. Afanas'ev V.G. Obshchestvo: sistemnost', poznanie i upravlenie. - M.: Politizdat, 1981. - S. 23.

3. Gegel' G.V.F. Filosofiya prava. M., 1990. S. 225.

4. Grudtsyna L.Yu. Razvitie institutov grazhdanskogo obshchestva v aspekte chastnogo i publichnogo prava // Obrazovanie i pravo. 2013. № 7(47).

5. Grudtsyna L.Yu. Chastnaya sobstvennost' i grazhdanskoe obshchestvo v Rossii // Advokat. 2009. № 8.

6. Lagutkin A.V. Rossiya na rasput'e: kuda poidem?-M.: Yurkompani, 2013. - S. 3.

7. Grudtsyna L.Yu. Grazhdanskoe obshchestvo i chastnoe pravo // Novyi yuridicheskii zhurnal. 2013. № 2.

8. $\quad$ Marks K. K evreiskomu voprosu // Marks K., Engel's F. Soch. T. 1. S. 390-391.

9. Pozdnyakov E.A. Rossiiskoe grazhdanskoe obshchestvo. Illyuzii i real’nost' // Politicheskii klass. 2006. № 22. - S. 6-7.

10. Shchuplenkov O.V., Shchuplenkov N.O. Konstitutsionnye osnovy informatsionnoi svobody v Rossii // NB: Voprosy prava i politiki. - 2013. - 10. - C. 35-92. DOI: 10.7256/2305-9699.2013.10.9617. URL: http:// www.e-notabene.ru/lr/article_9617.html

11. Lapin A.E., Petrova Yu.A. K voprosu o realizatsii polnomochii predstavitel'nykh organov mestnogo samoupravleniya v Rossiiskoi Federatsii // Administrativnoe i munitsipal'noe pravo. - 2011. - 4. - C. 24-33.

12. Grudtsyna L.Yu., Petrov S.M. Vlast' i grazhdanskoe obshchestvo v Rossii: vzaimodeistvie i protivo- stoyanie // Administrativnoe i munitsipal'noe pravo. - 2012. - 1. - C. 19-29.

13. Bondarchuk I.V. Legalizatsiya obshchestvennykh organizatsii i politicheskikh partii $\mathrm{v}$ mekhanizme zashchity konstitutsionnogo stroya Ukrainy // NB: Voprosy prava i politiki. -2013 . - 6. - C. 135-151. DOI: 10.7256/2305-9699.2013.6.6292. URL: http://www.e-notabene.ru/lr/article_6292.html

14. I. D. Koroeva Filosofiya vzaimodeistviya vlasti i naroda // Politika i Obshchestvo. - 2012. - 4. - C. 18-24.

15. Trofimov V.V. Uchastie struktur grazhdanskogo obshchestva v pravoobrazuyushchikh pravootnosheniyakh kak forma vyrazheniya narodovlastiya // NB: Voprosy prava i politiki. - 2012. - 5. - C. 147-170. URL: http://www.e-notabene.ru/lr/article_364.html 